\title{
Structural eQuivalence and the NeO-PI-R: IMPLICATIONS FOR THE APPLICABILITY OF THE FIVE-FACTOR MODEL OF PERSONALITY IN AN AfRICAN CONTEXT
}

\author{
SUMAYA LAHER \\ Department of Psychology \\ University of the Witwatersrand \\ South Africa \\ Correspondence to: Sumaya Laher \\ e-mail: sumaya.laher@wits.ac.za
}

\begin{abstract}
The NEO-PI-R is one of the most widely used and researched operationalisations of the Five Factor Model (FFM) of personality (McCrae \& Allik, 2002, McCrae \& Terraccianno, 2005). Considerable evidence exists in terms of its replicability across cultures leading researchers to conclude that the NEO-PI-R and by extension the FFM are universally applicable. This paper, by virtue of reviewing appropriate literature, argues that evidence for the structural equivalence of the NEO-PI-R, while appropriate in Western cultures, is lacking in non-Western, and specifically African cultures. This is discussed with particular reference to the existence of other factors which are not tapped by this model and which would merit further research.
\end{abstract}

Keywords: Five-Factor Model, individualism, collectivism, personality, spirituality

In the past century, psychology has taken to a more scientific exploration of personality and consequently, theories about personality abound. It can be argued though that presently the trait theory of personality dominates the field of personality psychology, particularly among those theorists working within an evolutionary and/or a cross-cultural psychological perspective (McCrae \& Terraccianno, 2005a, 2005b; Rolland, 2002). Within the trait perspective, the Five-Factor Model (FFM) is at the forefront of research. The NEO-Personality Inventory (NEO-PI-R) is amongst the most widely used and researched operationalisations of the FFM. Evidence from studies using the NEO-PI-R suggests that the FFM is cross-culturally applicable. This paper examines this argument specifically from an equivalence perspective and argues, by virtue of reviewing relevant literature, that evidence for the structural equivalence of the FFM as operationalised by the NEO-PI-R is lacking in an African context. The paper also argues that while the FFM might have some universal applicability, it is not exhaustive enough. If a model is to be truly universal and exhaustive, there are other factors that may need to be taken into account.

\section{THE FIVE-FACTOR MODEL}

Over the years theorists have sought to identify the common personality traits and numerous debates as to the number of traits exist. Before the dominance of the FFM, Cattell's theory in support of 16 personality factors was commonly accepted. However, the vast amount of empirical and theoretical literature of late supporting the FFM has propelled this theory into prominence. Although evidence in favour of an FFM of personality has been accumulating for the past fifty years, the 1980s marked the beginning of a new era for research into the FFM, largely through the work of theorists like Digman, Costa, McCrae and Goldberg (Church, 2000; McCrae \& Allik, 2002). According to McCrae and Costa (1990, cited in McCrae, Costa, Del Pilar, Rolland, \& Parker, 1998), "the FFM is an organisation of personality traits, and traits in turn are dimensions of individual differences in tendencies to show consistent patterns of thoughts, feelings, and actions" (p. 173). McCrae (2001) further defines traits as "endogenous basic tendencies that, within a cultural context, give rise to habits, attitudes, skills, beliefs, and other characteristic adaptations" (p. 819). Thus, traits are relatively stable, enduring individual differences in thoughts, feelings and behaviours (Church, 2000). Different theorists sometimes give different names to the underlying five factors. However, the creation of the NEO-Personality Inventory (NEOI) by Costa and $\mathrm{McCrae}$ went some way towards bringing about consensus as to the labels attached to the five factors (Church, 2000; Rolland, 2002).

In brief, the five factors are: neuroticism or emotional stability, extraversion, openness to experience, agreeableness, and conscientiousness (Church, 2000; Costa \& McCrae, 1992; Rolland, 2002). Neuroticism, or emotional stability, is defined as a general tendency to experience negative affects such as fear, sadness, embarrassment, anger, guilt and distrust. It is the degree to which a person is calm and self-confident as opposed to anxious and insecure. Extraversion is regarded as a general tendency toward sociability, assertiveness, activeness and being talkative. It is therefore the degree to which a person is sociable, leader-like and assertive as opposed to withdrawn, quiet and reserved. Individuals willing to entertain novel ideas and unconventional values are described by the openness to experience trait. Sometimes referred to as "intellectance", it is the degree to which a person is imaginative and curious as opposed to concrete-minded and narrow-thinking. Agreeableness encapsulates constructs of sympathy, cooperativeness and helpfulness towards others. It is described as the degree to which a person is good-natured, warm and cooperative as opposed to irritable, uncooperative, inflexible, unpleasant and disagreeable. The final factor, conscientiousness, may be described as the degree to which a person is persevering, responsible and organised as opposed to lazy, irresponsible and impulsive. This dimension summarises the more specific traits that mark careful, responsible and dependable people in contrast to people who are lazy and lack self-discipline. It is sometimes also described as a general tendency toward academic and occupational achievement, but this description has often come under dispute (Costa \& McCrae, 1992; McCrae et al., 1998; Rolland, 2002).

Van de Vijver and Rothmann (2005) argue that one needs to establish the equivalence of an instrument if it is to be applied cross-culturally. Within personality psychology, the three categories of equivalence (structural, metric and scalar equivalence) as defined by Van de Vijver and Leung (1997) have been most influential. Structural equivalence refers to the 
extent to which an instrument measures the same construct across cultures and is, according to Poortinga, Van de Vijver and Van Hemert (2002) the minimum requirement for any comparison. Metric equivalence requires not only that the construct be replicable but also that the distance between the scale points on which the construct is measured be the same across cultures. Finally, scalar equivalence requires that "a score has precisely the same meaning, even quantitatively, in terms of an interpretation, independent of the cultural background the respondent from whom that score was obtained" (Poortinga et al., 2002, p. 292). Scalar equivalence is different to metric equivalence in that it requires a joint zero-point across cultures (Poortinga et al., 2002). Hence, this paper discusses the structural equivalence of the NEO-PI-R to inform debate on the cross-cultural applicability of the FFM.

\section{STRUCTURAL EQUIVALENCE OF THE NEO-PI-R}

In general, research on the Five-Factor Model, utilising the NEO-PI-R, has been promising. McCrae and Costa (1997) compared the American factor structure of the NEO-PI-R with the factor structures from the German, Portuguese, Hebrew, Chinese, Korean and Japanese samples and found similar structures. They concluded that because the samples studied represented highly diverse cultures with languages from five distinct language families, the data and results obtained strongly suggest that a five-factor personality trait structure is universal.

McCrae, Yik, Trapnell, Bond and Paulhus (1998) also cite research in support of the fact that the Five-Factor Model is replicable not only in different languages but in languages from entirely different families, including Sino-Tibetan, Hamito-Semitic, Uralic and Malayo-Polynesian. Similarly, Church and Lonner (1998) cite a number of studies that indicate that the structure of translated versions of the NEO-PI has been replicated well in the Dutch, German, Italian, Estonian, Finnish, Spanish, Hebrew, Portuguese, Russian, Korean, Japanese, French and Filipino cultures.

In a recent publication, McCrae and Allik (2002) bring together 14 papers representing 40 cultures, 5 continents, and IndoEuropean, Altaic, Uralic, Hamito-Semitic, Malayo-Polenesian, Dravidian, Austro-Asiatic, Sino-Tibetan, Japanese, Korean and Bantu languages. Evidence from these papers suggests that the FFM does generalise well, but according to McCrae and Allik (2002) specific variations do exist. A paper by Rolland (2002) cites evidence in favour of the generalisability of the $\mathrm{N}, \mathrm{O}$ and $\mathrm{C}$ dimensions after Varimax rotation but not for the $\mathrm{E}$ and $\mathrm{A}$ dimensions.

Church (2000) also reports that the five dimensions have been found in several European languages, but the cross-cultural comparability of the Intellect/Openness dimension was less definitive than the others. He cites research that identified a "Big Seven" model, comprised of Positive Valence, Negative Valence and five dimensions similar to the Five-Factor Model. More recently, Ashton and Lee (2005; 2007) found support for a five-factor model, but proposed some differences in the Agreeableness and Neuroticism factors and suggested the presence of a sixth factor identified in the study as an HonestyHumility dimension leading to the establishment of the HEXACO model.

McCrae and Terraccianno (2005a), in a study incorporating data from 36 countries, report that the five factors are generally common to all people. However, five of the African countries assessed in their article (Botswana, Nigeria, Burkina Faso, Ethiopia and Uganda) exhibited notably lower factor congruence coefficients. It should be noted that none of the African participants in the study took the test in their native language. The NEO-PI-R was completed in English and, in the case of Burkina Faso, French. Studies in the South African context have consistently demonstrated how taking a test in a language that is not one's home language and in which one is not necessarily proficient affects responses to test items (see Abrahams, 1996, 2002; Abrahams \& Mauer, 1999a, 1999b; Bedell, Van Eeden \& Van Staden, 1999; Foxcroft, 2004; Meiring, Van de Vijver \& Rothmann, 2006; Nell, 1999; Van de Vijver \& Rothmann, 2004).

Heaven and Pretorius (1998) found support for the five factors in an Afrikaans-speaking South African sample, but found that the five factors did not replicate well for a Sotho-speaking South African sample. According to Heaven and Pretorius (1998), the clearest factor to emerge in the Sotho sample was an emotional stability factor. Matsimbi (1997) found only three of the five factors, namely Extraversion, Conscientiousness and Agreeableness, in a sample of South African white-collar workers. Taylor (2000) investigated the construct comparability of the NEO-PI-R for black and white employees. Using a principal components analysis with oblimin rotation, Taylor (2000) found that the five factor structure emerged for the white sample but not for the black sample. The Openness dimension particularly could not be retrieved. A study by Heuchert, Parker and Stumpf (2000) indicated support for the Five-Factor Model on a sample of South African university students, but the factor structure was more clearly replicated for white students than for black students, with Openness to Experience weakly replicated in the black student sample. Heuchert et al. (2000) comment on the fact that methodological differences, particularly with regard to different factor-rotation methods, may account for the differences in results found in South African samples.

However, in all the studies cited above, language proficiency in English is cited as playing a role in the observed differences. These studies do not, however, underestimate the role of true cultural differences.

Other African studies also suggest that although the five-factor structure may be applicable, the essence of the factors may be different. For example, an unpublished master's study by Teferi (2004) using a Tigrignan translation of the NEO-PI-R in Eritrea, found evidence for a five-factor structure using an exploratory factor analysis with varimax rotation. However, only three of the factors, namely Neuroticism, Agreeableness and Conscientiousness, were replicated in his Eritrean sample. The Extraversion and Openness to Experience domains were poorly represented. Piedmont, Bain, McCrae and Costa (2002) found similar results with a Shona translation of the NEOPI-R in Zimbabwe. Although the five-factor structure was obtained, Extraversion and Agreeableness did not replicate as well as Neuroticism, and Conscientiousness and Openness to Experience replicated poorly.

Piedmont et al. (2002) cite a number of reasons for these results. The first of which has to do with the general adequacy of the translation, which may have been lacking. Alternatively, they suggest the possibility that the Shona language may lack equivalent terms for the English-language items. This concurs with findings by Teferi (2004) on the Eritrean translation, as well as an unpublished thesis which examined a Xhosa translation of the NEO-PI-R (Horn, 2000). A common criticism levelled against the FFM is that it is an approach developed from the analysis of adjective terms in the English language.

Piedmont et al. (2002) also allude to the possibility that differences may occur in response styles and response biases in African samples. Allik and McCrae (2004) argue that acquiescent response biases as well as a tendency to avoid extreme responses are more prominent in collectivistic cultures; however, the issue of metric equivalence has yet to be fully explored in an African context. Finally, Piedmont et al. (2002) posit the possibility that some of the constructs measured by the NEO-PI-R may have no counterpart in the Shona culture especially at the facet level. They cite the example of Excitement Seeking (an essentially self- 
centred motivation), which is foreign in collectivistic cultures. Teferi (2004) also found Excitement Seeking problematic in the Tigrignan translation, both in terms of translation as well as replication. Piedmont et al. (2002) also discuss the weak replicability of Openness to Experience, suggesting that this is a heritable trait but that its development may be primarily related to urbanisation and industrialisation and would therefore not feature in non-industrialised, agrarian cultures. Whilst this may be a possibility for certain parts of Africa, it is certainly not the case for a large part of the continent, particularly in South Africa where the studies cited were conducted on relatively urbanised and industrialised individuals. Allik and McCrae (2004) suggest the possibility that traits like Extraversion and Openness to Experience are more valued and therefore more readily endorsed in Western cultures, whereas cooperation and tradition are more valued in non-Western cultures. However, both McCrae and Terraccianno (2005a) and Allik and McCrae (2004) acknowledge the possibility that there may be some African personality structures that differ from the FFM.

Thus, there is a body of evidence that suggests the structural equivalence of the NEO-PI-R in an African context deserves further research and attention. The FFM does seem to hold promise for the field of personality psychology, more so in light of accumulating evidence with regard to its universal applicability (see Ashton \& Lee, 2005; McCrae \& Allik, 2002; McCrae \& Terraccianno, 2005a, 2005b). However, evidence also suggests that the model is not exhaustive enough, particularly when it comes to Asian and African cultures (see Ashton \& Lee, 2007; Church, 2000; Cheung, 2004; McCrae \& Terraccianno, 2005; Meiring, Barrick \& Rothmann, 2005; Piedmont et al., 2002; Poortinga et al., 2002; Rolland, 2002; Saucier \& Skrzypinska, 2006; Teferi, 2004).

\section{NON-WESTERN VIEWS OF PERSONALITY}

Saraswathi (1998) argues that in the West the focus is on an independent, autonomous self, characterised by motivation, analytical, abstract thinking and an internal locus of control. Shweder and Bourne (cited in Hermans \& Kempen, 1998) refer to the Western self as egocentric and the self of other cultures, particularly the Indian culture, as sociocentric. Piedmont et al. (2002) allude to this when they refer to the Shona culture as collectivist, sociocentric and group-cohesive. Terms of this sort currently abound in cross-cultural literature, but the classification by Triandis (1989) and Markus and Kitayama $(1991,1998)$ has been the most influential.

Triandis (1989) suggests that a distinction can be drawn between individualism and collectivism, where individualists give priority to personal goals over the goals of collectives. Collectivists either make no distinctions between personal and collective aims, or if such distinctions are made, they subordinate personal aims to those of the collective to which they belong. In a similar vein, Markus and Kitayama $(1991,1998)$ suggest that with people from an Euro-American culture the emphasis is on independence, while in many Asian cultures the focus is on interdependence. Whereas Americans may seek to maintain their independence from others by attending to their individual selves and expressing their inner attributes, Asians emphasise attention to others, fitting in, and maintaining harmonious relationships.

The clearest example of this comes from the work of Fanny Cheung and colleagues and the development of the CrossCultural Personality Inventory-2 (CPAI-2) (Cheung, 2004; Cheung, Cheung, Howard \& Lim, 2006). Cheung et al. (2001) argue that while the FFM was recoverable using the NEOPI-R in a Chinese setting, it did not provide a comprehensive description of personality. What was most notably lacking were the interdependent aspects of Chinese culture and, by extension, the Chinese personality. Following extensive research into personality structure in China, the CPAI was developed and revised to form the CPAI-2 (see Cheung, Leung, Fan, Song, Zhang \& Zhang, 1996; Cheung et al., 2001; Cheung, 2004). This inventory revealed a clear Interpersonal Relatedness factor that did not load on any of the NEO-PI-R scales (Cheung, 2004; Cheung et al., 2001). Scales loading on this factor were Ren Qing (relationship orientation), Harmony, Tradition vs Modernity, Social Sensitivity, Discipline and Thrift vs Extravagance. The characteristics associated with these personality scales reflect a strong orientation towards instrumental relationships, avoidance of external, internal and interpersonal conflict and adherence to norms and traditions (Cheung et al., 2001). Cheung (2004) also reports that a combination of the FFM factors could not adequately predict the variance of the Interpersonal Relatedness factor scales.

Mpofu (2001) provides evidence for the existence of a collectivist dimension to the Shona culture in Zimbabwe. In South Africa, this collectivistic dimension is best captured by the indigenous term, 'ubuntu' (humanness), which originates from an African aphorism, 'umuntu ngumuntu ngabantu' (Zulu version) or 'motho ke motho ka batho' (Sotho version), which translates as 'a person is a person through persons', or as African philosophers say, 'I am because we are' (Louw, 2001; Shutte, 2001). However, Louw (2001) cautions against viewing 'ubuntu' as a purely collectivist dimension in direct opposition to Cartesian individualism. According to Louw (2001), the concept of 'ubuntu' defines the individual in relation to others where the individual "signifies a plurality of personalities corresponding to the multiplicity of relationships in which the individual in question stands (p. 6)." An individual is self-determining through other-dependence. Persons depend on relationships with other persons to grow as persons (Shutte, 2001). 'Ubuntu', in as far as it is concerned with relationships towards others, is defined by reverence, respect, sympathy, tolerance, loyalty, courtesy, patience, generosity, hospitality and cooperativeness. 'Ubuntu', as it manifests within the individual, is defined by an integrity and wholeness of character that is present in one's judgements, decisions and feelings and provides one with a sense of confidence, value and dignity (Shutte, 2001).

'Ubuntu' is not an absolute collectivist dimension that subsumes the individual and subjects everyone to a communal identity. Rather 'ubuntu' incorporates dialogue and promotes the functioning of the individual in the community, giving precedence to the community. Hence the African preference for cooperation and group work (shosholoza) or as a Sepedi (Northern Sotho) saying dictates: 'Feta kgomo o tshware motho' (if one is faced with a decisive choice between wealth and the preservation of life, then one should opt for the preservation of life) (Louw, 2001, p. 6). This understanding of 'ubuntu' collectivism correlates with recent research on individualism and collectivism, which has demonstrated that both concepts have sub-dimensions and are not merely bipolar constructs and that variation on dimensions of individualism and collectivism can occur across and within cultures (see Green, Deschamps \& Paez, 2005).

Also central to African personality, and something that is not covered by the FFM in particular, is the spiritual dimension. In 1969, Sow proposed an African model of personality where the individual is shaped by four principles with the first representing the body, the second being a vitality principle linked to physiological functioning, the third another vitality principle akin to psychological functioning and the final, inner layer being that of the spiritual principle. According to Sow, these concentric layers of the personality are in constant interaction with the environment (ancestors, family and community). Ajani -ya-Azibo (1991) postulated the requisites for a meta-theory of the African personality that was not too different from Sow's (1969). Ajani-ya-Azibo (1991) emphasises the need to adopt a black perspective on personality, also positing that personality has a biogenetic basis and that there 
is a natural order of all things. It is also emphasised that an African personality meta-theory must explain the nature of the spiritual essence underlying human personality. The interplay between the spiritual, mental, and physical dimensions of the human being and how this interplay influences personality and psychological functioning needs to be addressed. Ogbonnaya (1994) also addressed this aspect to some extent, citing many examples where the spiritual realm influences both the development of the person as well as his/her functioning in the environment. More recently, Mkhize (2004) presented an African metaphysical ontology that also emphasises the role of the spiritual dimension in shaping the individual.

\section{CONCLUSION}

In conclusion, it is apparent that in terms of structural equivalence, the NEO-PI-R, and by extension the FFM, is only partially applicable in an African, and more specifically a South African, context. There is evidence to suggest that elements of the five factors may manifest differently in an African context, if manifested at all. Furthermore, research indicates the potential presence of other factors not necessarily covered in the FFM. Therefore, I would argue in concordance with Cheung, Cheung, Leung, Ward and Leong (2003) that there is a necessity for research investigating not only the universal applicability of Western theories and instruments (the etics) but also the necessity for investigating the possibility of other personality factors not addressed by Western models that may be indigenous to specific cultures (the emics) or which may in themselves prove to be additions to the etics. Furthermore, there is an urgent need for research not only into personality instruments but into the creation of an African theory of personality.

With regards to this, two South African initiatives deserve to be mentioned: The first is the recent construction of the Basic Traits Inventory (BTI, see Taylor \& De Bruin, 2005). The BTI is an English-language measure of the FFM developed in South Africa. It has a hierarchical structure similar to the NEO-PI-R with five broad traits on the highest level and 24 facet scales on a lower level. Taylor and De Bruin (2005) attempt to maximise the cross-cultural suitability of the BTI by screening all items for appropriateness with regard to content and comprehensibility, presenting the items in content blocks, avoiding reverse scored items and clearly labelling the response categories of the fivepoint Likert scale. Research has demonstrated that the five factors as measured by the BTI can be extracted across the diversity of cultures in South Africa (see De Bruin, Schepers \& Taylor, 2005; Ramsay, Taylor, De Bruin \& Meiring, 2005). This pseudo-etic approach, while promising, still does not address whether or not the five factors are a comprehensive representation of personality in a South African context.

A second initiative that holds promise in this area is the South African Personality Inventory Project (SAPI). The project aims at developing a single, unified personality inventory for South Africa that incorporates both universal (etic) and unique (emic) personality factors found across the diverse cultures. The first stage of this project is underway and aims to explore indigenous perceptions of personality as comprehensively as possible (see Meiring, 2006). According to Meiring (2006), a study exploring personality conceptions in the three main Nguni languages (Swati, Xhosa and Zulu) revealed 26 clusters of persondescriptive terms centred around the social-relational aspects of personality, most notably altruism, empathy, harmony and guidance.

Therefore the future for personality psychology in South Africa, particularly in terms of contributions towards the FFM, looks promising, with researchers set to contribute pertinent and interesting results to the local and international arenas.

\section{ACKNOWLEDGEMENTS}

I wish to thank the reviewers for their useful comments on the first draft of this paper.

\section{REFERENCES}

Abrahams, F. (1996). The cross-cultural applicability of the 16 Personality Factors Inventory (16PF). Unpublished doctoral thesis, University of South Africa, Pretoria, South Africa.

Abrahams, F. (2002). The (un)fair usage of the 16PF (SA92) in South Africa: A response to C.H. Prinsloo and I. Ebersöhn. South African Journal of Psychology, 32, 58-61.

Abrahams, F. \& Mauer, K.F. (1999a). The comparability of the constructs of the 16PF in the South African context. Journal of Industrial Psychology, 25, 53-59.

Abrahams, F. \& Mauer, K.F. (1999b). Qualitative and statistical impacts of home language on responses to the items of the Sixteen Personality Factor Questionnaire (16PF) in South Africa. South African Journal of Psychology, 29, 76-86.

Ajani-ya-Azibo, D. (1991). Towards a metatheory of African personality. Journal of Black Psychology, 17, 37-45.

Allik, J., \& McCrae, R. R. (2004). Toward a geography of personality traits. Patterns of profiles across 36 cultures. Journal of Cross-Cultural Psychology, 35, 13-28.

Ashton, M.C. \& Lee, K. (2005). Honesty-Humility, the Big Five, and the Five Factor Model. Journal of Personality, 73, 1321-1353.

Ashton, M.C. \& Lee, K. (2007). Empirical, theoretical, and practical advantages of the HEXACO model of personality structure. Personality and Social Psychology Review, 11, $150-166$.

Bedell, B., Van Eeden, R. \& Van Staden, F. (1999). Culture as a moderator variable in psychological test performance: Issues and trends in South Africa. South African Journal of Industrial Psychology, 25, 1-7.

Cheung, F., Cheung, K., Fan, R., Song, W., Zhang, J.X. \& Zhang, J.P. (1996). Development of the Chinese Personality Assessment Inventory. Journal of Cross-Cultural Psychology, 27, 181-199.

Cheung, F., Cheung, S., Leung, K., Ward, C. \& Leong, F. (2003). The English version of the Chinese Personality Inventory. Journal of Cross-Cultural Psychology, 34, 433-452.

Cheung, F.M. (2004). Use of Western and indigenously developed personality tests in Asia. Applied Psychology: An International review, 53(2), 173-191.

Cheung, F.M. \& Leung, K. (1998). Indigenous personality measures: Chinese examples. Journal of Cross-Cultural Psychology, 29, 32-62.

Cheung, F.M., Leung, K., Zhang, J.X., Sun, H., Gan, Y., Song, W. \& Xie, D. (2001). Indigenous personality constructs: Is the Five Factor model complete? Journal of Cross-Cultural Psychology, 32, 407-433.

Cheung, S., Cheung, F., Howard, R. \& Lim, Y.H. (2006). Personality across the ethnic divide in Singapore: Are "Chinese traits" uniquely Chinese? Personality and Individual Differences, 41, 467-477.

Church, T.A. (2000). Culture and personality: Toward an integrated cultural trait psychology. Journal of Personality, $68,651-704$.

Costa, P.T. \& McCrae, R.R. (1992). NEO-PI-R Professional Manual. Florida, Psychological Assessment Resources.

De Bruin, G.P., Schepers, J.M. \& Taylor, N. (2005). Construct validity of the $16 \mathrm{PF} 5^{\text {th }}$ edition and the Basic Traits Inventory. Paper presented at the 8th Annual Industrial Psychology Conference, June, Pretoria, South Africa.

Foxcroft, C. (2004). Planning a psychological test in the multicultural South African context. South African Journal of Industrial Psychology, 30, 8-15.

Green, E.G.T., Deschamps, J-L. \& Páez, D. (2005). Variation of individualism and collectivism within and between 20 
countries: A typological analysis. Journal of Cross-Cultural Psychology, 36, 321-339.

Heaven, P.C. \& Pretorius, A. (1998). Personality structure among black and white South Africans. The Journal of Social Psychology, 138, 664-666.

Hermans, H.J.M. \& Kempen, H.J.G. (1998). Moving cultures: The perilous problems of cultural dichotomies in a globalising society. American Psychologist, 53, 1111-1120.

Heuchert, J.W.P., Parker, W.D. \& Stumpf, H. (2000). The Five Factor model of personality in South African college students. American Behavioural Scientist, 44, 112-125.

Horn, B.S. (2000). A Xhosa translation of the NEO-PI-R: A pilot study. Unpublished master's thesis: University of Port Elizabeth, South Africa.

Louw, D.J. (2001). Ubuntu and the challenges of multiculturalism in post-apartheid South Africa. Retrieved January 25, 2007 from the World Wide Web: http://www.phys.uu.nl/ unitwin/ubuntu.html

Markus, H.R. \& Kitayama, S. (1991). Culture and self:Implications for cognition, emotion and motivation. Psychological Review, 98, 224-253.

Markus, H.R. \& Kitayama, S. (1998). The cultural psychology of personality. Journal of Cross-Cultural Psychology, 29, 63-87.

Matsimbi, W.E. (1997). Cross-cultural generalisability of the Five Factor model: A study on South African white collar males. Unpublished master's dissertation. University of the Witwatersrand, Johannesburg.

McCrae, R.R. (2001). Trait psychology and culture: Exploring intercultural comparisons. Journal of Personality, 69, 819-846.

McCrae, R.R. \& Allik, J. (2002). The Five-Factor Model of personality across cultures. New York: Kluwer Academic.

McCrae, R.R. \& Costa, P.T. (1997). Personality trait structure as a human universal. American Psychologist, 52, 509-516.

McCrae, R.R. \& Terracciano, A. (2005a). Universal features of personality traits from the observers perspective: Data from 50 cultures. Journal of Personality and Social Psychology, $89,547-561$.

McCrae, R.R. \& Terracciano, A. (2005b). Personality profiles of cultures: Aggregate personality traits. Journal of Personality and Social Psychology, 89, 407-525.

McCrae, R.R., Yik, M.S., Trapnell, P.D., Bond, M.H. \& Paulhus, D. (1998). Interpreting personality profiles across cultures: Bilingual, acculturation, and peer rating studies of Chinese undergraduates. Journal of Personality and Social Psychology, $74,1041-1055$

Meiring, D. (2006). South African Personality Inventory Project. Retrieved October 11, 2007 from the World Wide Web: http://www.meiringd.co.za/sapi.htm

Meiring, D., Van de Vijver, F.J., \& Rothmann, S.R. (2000). Bias in an adapted version of the 15FQ+ questionnaire in South Africa. South African Journal of Psychology, 36, 340-356.

Meiring,D., Van de Vijver, F, Rothmann, S., \& Barrick, M.R. (2005). Construct, item and method bias of cognitive and personality tests in South Africa. South African Journal of Industrial Psychology, 31, 1-8.
Mkhize, N.J. (2004). Culture and the self in moral and ethical decision-making: A dialogical approach. Unpublished $\mathrm{PhD}$ dissertation. University of Kwazulu-Natal, South Africa.

Mpofu, E. (2001). Exploring the self concept in African culture. The journal of genetic psychology, 155, 341-354.

Nell, V. (1999). Standardising the WAIS-III and the WMS-III for South Africa: Legislative, psychometric and policy issues. South African Journal of Psychology, 29, 128-137.

Ogbonnaya, A.O. (1994). Person as community: An African understanding of the person as an intrapsychic community. Journal of Black Psychology, 20, 75-87.

Piedmont, R.L., Bain, E., McCrae, R.R. \& Costa, P.T. Jr. (2002). The applicability of the Five Factor Model in a sub-Saharan culture: The NEO-PI-R in Shona. In R.R. McCrae \& J. Allik (Eds.). The Five-Factor Model of personality across cultures. New York: Kluwer Academic. pp. 155-175.

Poortinga, Y.H., Van de Vijver, F. \& Van Hemert, D.A. (2002). Cross cultural equivalence of the Big Five: A tentative interpretation of the evidence. In R.R. McCrae \& J. Allik (Eds.). The Five-Factor Model of personality across cultures. New York: Kluwer Academic. pp. 281-303.

Ramsay, L.J., Taylor, N., De Bruin, G.P. \& Meiring, D. (2005). The big five personality factors at work: A South African validation study. Poster presentation at the International Symposium on Personality at Work 2005, May, Lueneburg, Germany.

Rolland, J.P. (2002). Cross-cultural generalisability of the Five Factor model of personality. In R.R. McCrae \& J. Allik (Eds.). The Five-Factor Model of personality across cultures. New York: Kluwer Academic. pp. 7-29.

Saraswathi, T.S. (1998). Many deities, one God: Towards convergence in cultural and cross-cultural psychology. Culture and Psychology, 4, 147-160.

Saucier, G., \& Skrzypinska, K. (2006). Spiritual but not religious? Evidence for two independent dispositions. Journal of Personality, 74, 1257-1292.

Shutte, A. (2001). Ubuntu: An ethic for a new South Africa. Pietermaritzburg, South Africa: Cluster Publications.

Sow, A.I. (1980). Anthropological Structures of Madness in Black Africa. New York: International Universities Press.

Taylor, I.A. (2000). The construct comparability of the NEO-PI-R questionnaire for black and white employees. Unpublished doctoral dissertation. University of the Orange Free State, South Africa.

Taylor, N. \& De Bruin, G.P. (2005). Basic Traits Inventory: Technical manual. Johannesburg: Jopie van Rooyen \& Partners, SA

Teferi, T.B. (2004). The application of the NEO-PI-R in the Eritrean context. Unpublished master's dissertation (Research Psychology). University of the Witwatersrand, Johannesburg.

Triandis, H.C. (1989). The self and social behaviour in differing contexts. Psychological Review, 96, 508-520.

Van de Vijver, F. \& Leung, K. (1997). Methods and data analysis for cross cultural research. Newbury Park, CA: Sage.

Van de Vijver, F. \& Rothmann, S. (2004). Assessment in multicultural groups: The South African Case. South African Journal of Industrial Psychology, 30, 1-7. 